\title{
LO QUE ENSEÑA LA REPÚBLICA ${ }^{1}$
}

\author{
Raúl Gutiérrez, El arte de la conversión. Un estudio de la República de \\ Platón, Lima: Fondo Editorial de la Pontificia Universidad Católica del \\ Perú, 365 pág., 2017.
}

\author{
Álvaro Vallejo Campos, Adonde nos lleve el logos. Para leer la República \\ de Platón, Madrid: Trotta, 361 pág., 2018.
}

Si tuviéramos que elegir los cien libros fundamentales de la filosofía de todos los tiempos, la República de Platón estaría en la lista. Si fueran los diez más importantes, la República figuraría también. Y si la enumeración, lúdica o seria, obligara a decidirse por los tres principales o los dos principales, la breve lista también incluiría la obra monumental que Platón tituló Politeía: organización de la pólis. El planteo central del diálogo gira alrededor de la coincidencia de la filosofía y el poder político, que "presupone la existencia de personas naturalmente dotadas para la filosofía, pero además un proyecto de formación para que esas personas desarrollen su potencial". Porque, desde la perspectiva del diálogo, la posibilidad de poner en marcha una pólis justa "está estrechamente ligada a la educación de los guardianes", es decir: gobernantes capaces de filosofar o filósofos dispuestos a gobernar. En este sentido, la República documenta una de las primeras discusiones en la Antigüedad acerca de la filosofía como disciplina que busca la justicia en el manejo de lo público, y que elabora críticamente sus propios contenidos, métodos y estrategias pedagógicas.

Las citas del párrafo anterior pertenecen, respectivamente, a Raúl Gutiérrez y a Álvaro Vallejo Campos, destacados especialistas en la filosofía de Platón que en los últimos años dieron a conocer dos trabajos de conjunto sobre la República, que condensan décadas de estudio y magisterio. Hoy, cuando la tendencia a la especialización de los saberes aísla y atomiza detalles y particularidades, es una grata noticia la elaboración de obras sistemáticas y de conjunto como éstas que -aun en sus manifiestas diferencias, en enfoque, estilo y propósito- se ponen por delante una tarea mucho más vasta y a la vez necesaria. Esto es, la de dar un sentido, una brújula para orientarse en el océano de las interpretaciones; las antiguas, las modernas y especial-

${ }^{1}$ DOI: https://doi.org/10.46553/sty.30.30.2021.p275-282

Stylos. 2021; 30 (30); pp. 275-282; ISSN: 0327-8859; E-ISSN: 2683-7900 
mente las innumerables lecturas contemporáneas, que se ciernen como una nube negra sobre el lector que quiera emprender, por fuera del círculo cerrado del intercambio académico, la lectura o relectura de este diálogo fascinante y complejo. Lo auspicioso de estos dos libros es que, incluso siendo el resultado de años de rigurosa labor científica, se proponen como guías accesibles también para los no iniciados: los que comienzan a estudiar filosofía, y los colegas que, sin ser especialistas en la Antigüedad, precisan un conocimiento actualizado sobre el estado de la cuestión relativo al diálogo y sus múltiples temas. O para estudiosos de otras áreas del saber (la República aborda cuestiones que hoy debaten disciplinas muy diversas). Igualmente grato y es casi un azar divino que estas dos obras que se ocupan del diálogo como una totalidad se publiquen en español: idioma que reúne potencialmente gran cantidad de lectores ávidos de orientación, pero está lejos de ser preponderante entre las lenguas de la divulgación científica.

El arte de la conversión, el ensayo de Raúl Gutiérrez (magister y doctor en Filosofía por las Universidades de Friburgo y Tubinga, profesor principal en la Pontificia Universidad Católica del Perú), comienza por señalar el carácter nuclear de los símiles de los libros centrales de la República, el sol, la línea y la caverna, para desarrollar a partir de ellos la clave hermenéutica que articula todo el diálogo. La conversión del título alude al girarse del "alma entera" que, según la imagen de la caverna, implica toda auténtica educación. Ella no consiste -se dice en la República- en "implantar la vista en ojos ciegos", como pretenden algunos falsos maestros, ya que nuestras almas no son ciegas: en ellas está la capacidad de ver, pero educarse significa dirigir esa visión hacia las realidades luminosas y no hacia lo más bajo y oscuro. La tesis de Gutiérrez es que la estructura literaria y argumentativa de toda la República depende (y remite tácitamente) a las divisiones presentes en las alegorías. Para los especialistas no hay dudas de que las tres alegorías están ligadas entre sí: son partes de una misma secuencia que busca clarificar la naturaleza del Bien, el mégiston máthema, la mayor cosa aprendida que se requiere para convertirse en guardián perfecto. Pero además, están conectadas por correspondencias analógicas en el nivel de los contenidos alegóricos: las clasificaciones que propone un símil se encuentran, reformuladas, en los otros dos. La explicación técnica de la imagen de la caverna ofrece un buen ejemplo de estas correspondencias. Gutiérrez da un paso más

Stylos. 2021; 30 (30); pp. 275-282; ISSN: 0327-8859; E-ISSN: 2683-7900 
allá cuando afirma que los libros que componen la República reproducen, en su organización y en su contenido, la jerarquía de las funciones cognoscitivas distinguidas en las alegorías (p. 36).

Así, según esta perspectiva, la discusión sobre la justicia en el libro I representa lo que en la imagen de la línea es el nivel de la eikasía. Para eso, Gutiérrez establece qué entiende por eikasía, polemizando con otras interpretaciones corrientes. A su juicio, la eikasía es semejante a la conciencia pre-reflexiva (p. 45), y en efecto -razona- las diferentes definiciones de justicia que proponen en el libro I se revelan como "meras sombras o imágenes" (p. 49), en la medida en que la regla que pretenden establecer puede verse, según la circunstancia, como justicia o como injusticia. Las concepciones que expresan Céfalo, Polemarco y Trasímaco "son meras sombras de la justicia, al igual que las imágenes que ellos proyectan de sí mismos".

Diferenciándose de la tesis de Kenneth Dorter, para quien el paralelo estructural de la pístis está dado por el conjunto de los libros II, III y IV, Gutiérrez entiende que el nivel de la creencia (pístis) no se extiende más allá del pasaje 434c9. En cambio, a su juicio, el final del IV, con el análisis del alma y sus partes, "corresponde a la primera subdivisión de lo inteligible, es decir, la diánoia" (p. 74). Esto es, "[m]ientras que las disputas en República I y, por consiguiente, en el nivel de la eikasía, son disputas sobre términos, y por ello sobre meras sombras", el libro II pasa a un nivel superior al preguntarse por el ser de la justicia y la injusticia, y por el poder que tienen cuando están en el alma. La indagación va así más allá de lo visible (donde se fija la pístis) e incursiona en lo inteligible (pp. 75-76). El análisis de la estructura interna del alma, al final del libro IV, se entiende aquí como representación de la diánoia que se dirige a los entes matemáticos. Gutiérrez cita a propósito a Konrad Gaiser: "lo matemático nace de o en el alma mediante una especie de reflexión del alma sobre su propia estructura" (p. 108). El lector puede identificar en esta referencia no sólo la proximidad con la tradición más reciente de la escuela de Tubinga -que en las últimas décadas del siglo XX fijó su atención en las llamadas doctrinas no escritas de Platón y en la teoría intraacadémica de los principios, e inspiró una relectura de todo el corpus platonicum a partir de ellas-, sino también la mirada neoplatonizante que busca ya en la República determinadas estrategias teóricas, como la auto-reflexión, que son rasgos que definen al platonismo de época imperial.

Stylos. 2021; 30 (30); pp. 275-282; ISSN: 0327-8859; E-ISSN: 2683-7900 
Gutiérrez encuentra en los cuatro primeros libros de la República una "topografía alegórica que corresponde al desarrollo del argumento" y a los tres primeros niveles onto-epistémicos de la línea (p. 86). A la vez, para que la multiplicidad de temas abordados en estos libros no ponga en riesgo la consistencia de la hipótesis, Gutiérrez se ocupa de algunos de ellos en particular para mostrar su coherencia con la totalidad topográfica, lo que de todos modos resulta muchas veces en importantes precisiones que contribuyen a la comprensión de temas difíciles de la República. Por ejemplo: a la noble mentira, que siendo una imagen funciona como los objetos de la eikasía (a pesar de integrar el tramo que la hipótesis asocia con la pístis) se la entiende como un "remedio de la falsedad verbal" y por lo tanto "como remedio de sí misma" (p. 86). Un poco más compleja resulta la aplicación plena de la hipótesis general a los libros centrales de la República. En el análisis del libro V se parte de la consideración del lógos que debe examinar los tres tipos de comunidades que regirán entre los guardianes de la pólis sana. Gutiérrez admite que, por ocuparse de temas estrictamente políticos, el libro V "parecería un retroceso en el ascenso del lógos hacia el ámbito inteligible y la Idea del Bien" (p. 131), sin embargo -argumenta- la base de las tres olas que debe superar el argumento es la suposición del Bien en sí. Al revés de lo que muestra la conversación, la hipótesis de la que se parte es la existencia de Ideas y su mutua comunidad, que recién aparece en $R$. VI 507b1-6. Claro que la concepción de la Idea en este nivel ("apariencia inteligible compuesta" de unidad y multiplicidad indeterminada, aunque "transparente de sentido"; pp. 191-192) y en particular, la de la Idea de Bien (como pura unidad e "Idea de Ideas"; p. 141) merecerían una discusión aparte.

Con todo, cuando se avanza hacia el aspecto dramático y argumental de los libros VI y VII, allí donde uno esperaría -siguiendo la clave hermenéutica que oficia de guía- ver plasmada la nóesis de manera patente, lo que muestra el diálogo es una profusión de imágenes. Oscuras (la de la nave, la planta, la bestia, la huérfana abandonada) o luminosas (el sol, la línea, la caverna), pero imágenes al fin. A mi juicio, esto pone en evidencia una paradoja de las lecturas neoplatónicas de la República, que abrevan en la belleza de su prosa metafórica para reformularla luego en términos de una dogmática que el propio Platón se niega a asumir. Pero remito al lector a atender las ra-

Stylos. 2021; 30 (30); pp. 275-282; ISSN: 0327-8859; E-ISSN: 2683-7900 
zones que ofrece El arte de la conversión en los tres capítulos que dedica a éste, el centro de su interpretación.

Además del análisis de los libros VIII y IX, los dedicados a la decadencia de los regímenes políticos, el ensayo dedica dos capítulos a las dos cuestiones del libro X: el lugar de la poesía mimética en la pólis y el fabuloso mito escatológico con el que cierra el diálogo. En cuanto a lo primero, Gutiérrez llama la atención sobre la "valoración positiva de la imagen, las apariencias, las artes" (pp. 258-259) que sobrevuela por encima y más allá de las críticas puntuales a la entronización de los poetas trágicos y del espectáculo de masas como forjadores de valores. Gutiérrez enfatiza la visión que propone la República del filósofo como imitador, que se vuelve ordenado y divino por su mímesis, y la elaboración mimética de la politeía. Y pone entre paréntesis, con lucidez y rigor textual, la expulsión de la poesía que tantos ríos de tinta ha estimulado, sobre todo en los siglos XX y XXI. En cuanto al mito de Er, Gutiérrez destaca su modo de amalgamar, en el final, el comienzo del diálogo ("Bajé ayer al Pireo...") con el centro (la imagen de la caverna), y su dimensión protréptica, es decir, su valor para "el arte de la conversión, que busca mover no sólo el intelecto sino el alma entera -con su racionalidad, su irascibilidad y sus apetitos- hacia la contemplación del ser y del Bien” (p. 262). Asimismo, y en implícita polémica con quienes han señalado posibles contradicciones entre la moraleja del relato escatológico y la visión de la justicia argumentada en el diálogo, Gutiérrez advierte que, en el contexto mítico, sólo un alma encarnada puede "transformarse según las condiciones de vida que haya elegido" (p. 271) y destaca el auxilio que en este sentido aporta la sensatez (phrónesis) propia del alma filosófica. A manera de epílogo y de apuesta a la continuidad de este proyecto hermenéutico, el último capítulo de El arte de la conversión se ocupa de la re-lectura de los símiles en el Parménides y a la supuesta "ruptura" de este diálogo tardío con la concepción de las Ideas expuesta en la madurez. Siempre desde la perspectiva de quienes se concentran en "la unidad de forma y contenido" del pensamiento platónico, Gutiérrez sostiene que no hay tal ruptura ni una autocrítica en lo relativo al estatuto de las Ideas sino una necesidad de mayor desarrollo (pp. 295-297), que de hecho el libro despliega en las treinta páginas finales.

Stylos. 2021; 30 (30); pp. 275-282; ISSN: 0327-8859; E-ISSN: 2683-7900 
A diferencia de El arte de la conversión, que se inscribe en una corriente interpretativa singular, el libro de Álvaro Vallejo Campos (doctor en Filosofía por la Universidad de Granada, en la que ha enseñado por décadas, traductor de Platón y de Aristóteles) se propone como una introducción global a la República. Esto es: dedica un capítulo a cada libro de la Politeía, y recorre puntualmente todos los temas allí desplegados, poniendo en balance las diferentes perspectivas críticas que dominan hoy el debate científico al respecto, sumando también los antecedentes de las visiones platónicas y, en muchos casos, el impacto que el texto tuvo en su tiempo o en la tradición filosófica occidental.

Vallejo Campos incluye la República en el género utópico, tal como lo concibe Karl Mannheim: como "un estado de espíritu que resulta incongruente con respecto a la realidad dentro de la cual se da", y cuya incongruencia deriva "del hecho de que tal estado de espíritu se orienta en el pensamiento y en la práctica a objetos que no existen en una situación real" ( $p$. 11). Esta definición parece coincidir con la observación que hace Glaucón hacia el final del libro IX de que la pólis justa descripta se encuentra básicamente "en las palabras". No obstante, Vallejo atiende también a las palabras de Sócrates en el libro VI: que no exista efectivamente esta pólis no quiere decir que lo dicho sean meros "castillos en el aire". En consonancia con esto, discute diferentes formas de comprender lo utópico de la República. La de Hans-Georg Gadamer, que ve el contenido político del diálogo como algo conscientemente impracticable, como puros "juegos racionales" que estimulan el pensamiento. O la visión de otra corriente que podría remitirse en última instancia a Leo Strauss y que entiende la República como fundamentación de una ética básicamente individual (pp. 19-20). Vallejo Campos encuentra estas visiones apolíticas de la Politeía platónica, muy extendidas en sus diferentes variantes, como una "empresa hermenéutica desesperada". Mario Vegetti la adjudicaba a la ansiedad de los platonistas del siglo XX por rescatar a Platón de la denuncia de totalitarismo que había planteado Karl Popper en 1945. Vallejo Campos insiste de manera convincente en que despojar a la Politeía de sus contenidos políticos positivos es un sinsentido. Lo cual, por otra parte, no preserva a los lectores de Platón ni del esfuerzo de comprensión ni del de la crítica. En este sentido, el volumen resulta de gran interés para filósofos que no se especializan en la Antigüedad y para todo

Stylos. 2021; 30 (30); pp. 275-282; ISSN: 0327-8859; E-ISSN: 2683-7900 
aquel que, desde otra disciplina, busca una aproximación al diálogo y a la filosofía política de Platón. Sólo en pos de no extender de más esta reseña, me atengo en lo que sigue sólo a unos pocos ejemplos ilustrativos sobre tema político, entre los muchos desarrollados en este valioso libro.

Toda la conversación aporética acerca de la justicia en el libro I es analizada por Vallejo Campos no sólo internamente sino en relación con sus antecedentes en el pensamiento griego. La respuesta de Céfalo (la justicia consiste en beneficiar a los amigos y perjudicar a los enemigos) se revela afín a lo expresado por la poesía lírica (Píndaro) y trágica (Esquilo; p. 43). En cambio la posición de Trasímaco (justicia es lo que conviene al más fuerte), que algunos han querido ver asociada con el Calicles del Gorgias, es remitida aquí al diálogo de los melios que narra Tucídides, y diferenciada de la postura de Calicles: esta última se aproxima a la idea de ley natural, en cambio la de Trasímaco representa una suerte de realismo o positivismo jurídico amoral (p. 45).

Así también, al introducir y comentar los presupuestos del realismo (la justicia no se cultiva voluntariamente; es preferible la injusticia a la justicia) que se desarrollan en el libro II, Vallejo Campos se detiene en cuestiones de mayor interés para la historia de la teoría política. Por ejemplo, en el planteo de Glaucón sobre el origen de la justicia, que incluye una alusión explícita a la noción de pacto social, de "tintes hobbesianos" (p. 55). El lector encuentra en estas páginas las referencias necesarias para poder indagar, por su parte, en los antecedentes de estas ideas en la sofística (Hipias, Antifonte) y en el pensamiento presocrático (de Anaximandro a Demócrito). O en las prefiguraciones de la "falsa teología" del inmoralismo que expone Adimanto en otros sofistas (Protágoras y Critias) y poetas (pp. 58-59). En cuanto a la génesis misma de la comunidad que ensaya Sócrates en el mismo libro II, Vallejo Campos no se hace eco de quienes, en años recientes, han querido ver la pólis de cerdos, en su saludable simpleza, como la pólis preferida por Sócrates o por Platón (entre otros, Donald Morrison y Christopher Rowe, con diferentes entonaciones, han reivindicado la validez de la pólis de cerdos). El argumento de la República, dice Vallejo Campos, "no pierde tiempo con ella" porque "el primitivismo no es una opción que Platón se tome en serio" (p. 62).

Stylos. 2021; 30 (30); pp. 275-282; ISSN: 0327-8859; E-ISSN: 2683-7900 
Las paradójicas comunidades del libro V, especialmente el "carácter político" que se le imprime al matrimonio, son desmenuzadas a la luz de sus efectos implícitos, como la "eugenesia" que Vallejo Campos no duda en atribuir al proyecto platónico (pp. 117-118). Al considerar la comunidad sexo-afectiva de los guardianes, Vallejo Campos no parece convencido por la visión benévola que algunos intérpretes quisieron hallar en la reivindicación de la "igualdad de las mujeres". Más bien encuentra en el comunismo de la República una renuncia al ideal socrático expresado en el Critón de guiarse por el "razonamiento que al reflexionar parece el mejor". Desde su perspectiva, parece haber una renuncia al consenso que pudiera implicar todo razonar en conjunto, y a lo provisional implícito en la contingencia de cada situación de razonamiento en concreto. Al contrario, la "ideología política holística" de la ciudad ideal (toma la expresión de Malcom Schofield) no se comparte por medio de la razón "ya que ésta llega de modo pleno sólo a unos pocos" (pp. 140-141).

Las distinciones del final del libro V -entre filósofos y filodoxos, entre realidades en sí y meras apariencias- contribuyen a delinear una "ontología del poder". Pero también a colocar la perspectiva platónica en un registro normativo, que no se contamina con la facticidad ni está "condicionado por lo que Kant llamaba la plebeya apelación a la experiencia" (p. 153). Es cierto también que de ese modo, el razonamiento de Platón parece escapar del yugo del statu quo y de la inercia de los prejuicios heredados, reforzados por la opinión generalizada y por la acrítica tenacidad del hábito. Si hay algo que queda de manifiesto al releer estos libros es que, más allá de los siglos transcurridos y de la comunidad concreta en la que se retome, la República sigue invitando a la audacia filosófica de pensar, y pensar contra la corriente.

Ivana Costa

UBA y UCA

Stylos. 2021; 30 (30); pp. 275-282; ISSN: 0327-8859; E-ISSN: 2683-7900 